\title{
Exploring the Impact of Handcraft Activities on the Creativity of Female Students at the Elementary Schools
}

\author{
Amir Rezaei \\ University of Malaya, Malaysia \\ E-mail: Am_rezaiee@yahoo.com \\ Manijeh Zakariaie \\ Islamic Azad University of Zanjan, Iran \\ E-mail: m_zakaryaei@yahoo.com
}

\begin{abstract}
Creativity has been one of the interesting issues in the field of education and has been subject of some studies. But studying the effect of using handcraft on the enhancing learners' creativity at early stages of education has not been focused on in many studies. Therefore, in this study an effort was made to explore the effect of using handcrafts on the enhancement of the creativity among the learners at elementary schools. The participants in this study were 64 female students who were selected randomly from elementary school learners at grade five in Tehran. For data collection Torrens Creativity Test was used and data gathering was done through pre-test and post-test. Data was analyzed by using descriptive statistics and ANOVA analysis. The data analysis revealed that using handcraft as an instrument was significantly effective in enhancing students' score in originality, flexibility and elaboration at the elementary grades, whereas; there was not any significant difference between their scores in fluency. The findings and their implications are discussed more in detail.
\end{abstract}

Keywords: Creativity, Originality, Flexibility, Elaboration, Fluency, Handcraft Making Activities

\section{Introduction}

One of the important goals of effective education in the modern world is to pave the way for the learner's creativity and improve the quality of life. Doubtlessly, achieving a constant development and improvement in the society in general and education in particular would not be possible through traditional methods in education in which they emphasize memorization and pre-described ways of learning.

In order to achieve the above mentioned goals in education, educators should focus more on training creative humans and learners because of the fact that these learners with new ideas and innovations can develop the world and with their new ideas can complement the existing knowledge in different fields.

In this regard, Tafler (1980) states that revolution in the information and electronics has made it difficult to predict and encounter contextual problems but the scholars in the practice believe that solution lies in our attention to creativity to enrich the educational environments (Hosseini, 2007).

Piage $(1960,1963)$, by emphasizing creative mind believes that training in general means trying to adjust the child with the adult society which he belongs to. Training means educating creative people no matter their number is not huge. Advanced education should train creative and innovative learners, not some obedient learners which follow the previously established rules and ideas (Khosronejad, 1995).

Torrance (1990), Mellow (1992) while criticizing the traditional education system stress that traditional methods should be modified and believe that education system should be directed toward creative education and learning.

Guillford (1965) believes that creativity consists of all of a person's characteristics and abilities. In fact, creativity from his point of view involves multidimensional thinking that is thinking from different aspects and dimensions. In his opinion, characteristics of a creative mind are: 1- originality 2- flexibility3- fluency4- elaboration.

In spite of the importance of creativity in solving individual and social problems, and in spite of the educators' and psychologists' emphasis on the growth of creativity through educational systems, unfortunately it has not been applied properly in most of the educational systems or there has been very weak performance in this field from the side of curriculum developers and policy makers.

Given the above-mentioned ideas, it seems to be the right time that the educators, authorities and policy makers in the practice take measures in order to make fundamental changes and modifications in attitudes and educational objectives and move toward creative thinking. Based on the findings of the researches done in the field, the appropriate time for the growth and development of creative thinking is elementary school age (Amiri, 2007). This 
is due to the fact that at this age learners at the elementary school have flexible cognition and identity. They are more subject to development, learning new things and acquiring new experiences. They are more keen on discovering new things and learning the concepts in their studies actively. This is the critical age that the foundation of creative thinking is laid.

In order to achieve these goals to establish the foundation of creative thinking, art has been used as an effective tool constantly. Studying the effectiveness of art as a strong instrument for activating learners in the process of learning and as important factor in the growth of creativity in elementary learners has been explored by many researchers. The signs of first attempts to use and attention to the utilization of art in education have been observed in the ancient Greece especially in the works of philosophers like Plato and Aristotle. After Plato and Aristotle, studying and stressing the importance of art in education was given importance by other philosophers and scholars.

By considering what was stated above about the importance of art in education in general and importance of creative thinking, the current study is an attempt to investigate the impact of art activities especially hand crafts on the creativity of the learners at the elementary schools.

In a definition of hand craft, Lancaster (1990) states that hand craft is learning and use of manual skills in making two or three dimensional objects and manual or mechanical instruments. In the other words, handcraft making puts art creativity in the access of the learners. By considering the statement of the problem, the hypotheses proposed for the current research are the following:

1- Use of art activities (handcraft) increases the grade three female students' scores in fluency

2- Use of art activities (handcraft) increases the grade three female students' scores in elaboration

3- Use of art activities (handcraft) increases the grade three female students' scores in originality

4- Use of art activities (handcraft) increases the grade three female students' scores in flexibility

5-Use of art activities (handcraft) increases the grade three female students' scores in creativity

\section{Methodology}

The population for this study consisted of elementary female students at grade three in zone five of Tehran city. Sampling was done randomly and subjects for the study were selected randomly from these groups of learners. On the whole, 64 students were selected for the purpose of the research. These participants were divided into two homogenous groups who had identical characteristics. Given the fact that the design of the study was experimental, one group acted as the experimental group and the other one acted as the control group. There were 33 students in experimental group and 31 students in the control group.

In the experimental group 32 handcraft activities were used as the independent variable. During the semester, they did hand crafting making activities with their teacher's assistance. The students were exposed to the handcraft making activities for twenty session, each session lasted one hour. The variables in the study consisted of different handcraft making activities with different items such as leaves, buttons, stones, colored paper, coconut skin, newspaper, vegetables, fruit seeds, dough, oyster, roots, mosaics, toy building, boxes, clothes, print etc).

Whereas, the students in the comparison group went through typical activities in the elementary school without receiving any treatment about handcraft making. Since in Iran's context they pay scant attention to the art subject in the elementary schools, consequently; in such classes teachers spend most of the time for talking about students' memories or spend time for discussing other subjects or sometimes do painting and drawing in the classes. Since the teachers usually do not have the knowledge and experience, most of the activities in the classroom are not professional i.e. they are mostly subjective without having any specific plan. Similarly, in the control group the students went through such typical activities.

In order to collect data for the purpose of the study, four pictorial tasks in Torrance Test (form A) were used. For analyzing the collected data, first descriptive statistics were used for determining the mean, variance and standard deviation of the scores. Also, inferential statistic analyses were used to calculate the significance of the differences by using two-way ANOVA.

\section{Results}

As stated before, five hypotheses were proposed for this research. Therefore, in order to test these hypotheses five analyses were done.

In order to test all the hypotheses to compare the mean score and performance of experimental and control groups, descriptive statistics were used. The result of the descriptive statistics revealed the mean score of both groups in different characteristics of creativity and both groups' score in the performance of different activities. Also, two-way 
ANOVA analysis was used to test the significance of the differences between the mean scores of the groups. This analysis which is also called factorial ANOVA is used when the researchers intends to investigate the impact of two factors on one outcome. Each hypothesis is tested and discussed separately in the following part.

\subsection{Hypothesis 1: Use of art activities (handcraft) increases the grade three female students' scores in fluency}

In order to test this hypothesis safely, it was turned to a null hypothesis so that testing it and rejecting it would be easier.

Null Hypothesis 1: Use of art activities (handcraft) doesn't increase the grade three female students' scores in fluency

Both groups were asked to do three activities. The result of both groups' performance revealed a difference between groups. On the whole, the experimental group's total score in different activities was higher than the comparison group. The result of descriptive data analysis showed that experimental group scored higher than control group in fluency test. The result of descriptive analysis has been indicated in table 1.

The result revealed that the experimental groups, $\mathrm{M}=8.60, \mathrm{SD}=3.56$ scored higher than the control group, $\mathrm{M}=8.19$, $\mathrm{SD}=3.63$. In order to find out the significance of the acquired differences, an ANOVA analysis was conducted. The result of the ANOVA analysis revealed that the F-value is .999. The acquired significance (sig) for the difference between groups is .319 which is more than the established value 0.05 . Therefore, it can be concluded that there is not a significant difference between experimental and control groups, F $(1,189)=.999$. Therefore, the proposed null hypothesis cannot be rejected. Accordingly, the first hypothesis is not supported that the use of art activities (handcraft) increases the grade three female students' scores in fluency.

\subsection{Hypothesis 2: Use of art activities (handcraft) increases the grade three female students' scores in elaboration}

The second hypothesis concerns the effect of hand craft activities on the students' improvement in elaboration. Like the first hypothesis this hypothesis was also turned into a null hypothesis so that we could test it statistically in a better and safer way.

Null Hypothesis 2: Use of art activities (handcraft) does not increase the grade three female students' scores in elaboration

To compare groups in terms of their ability in "elaboration", after finishing the treatment sessions the participants in each group were asked to perform four different activities and then they were assessed on their performance of each activity. Their performance at each activity was assessed and scored and their average score for all the activities was calculated and then their means were compared. Table 3 summarizes the result of descriptive statistics for the second hypothesis. The mean of the scores between two groups shows that mean of the scores in the experimental group, $\mathrm{M}=3.47, \mathrm{SD}=.95$ was higher than the mean of the scores in the control group, $\mathrm{M}=3.11$. $\mathrm{SD}=.96$.

But in order to see if this difference is significant, another ANOVA analysis was taken. The result has been displayed in table 4. The observed $\mathrm{F}$ value is 15.41. and the observed significance is less that the established significance 0.05 . Therefore it can be concluded that there is significant difference between the mean scores of the experimental and control groups, $\mathrm{F}(1,252)=15.41, \mathrm{P}<0.005$. Consequently, the null hypothesis is rejected and accordingly the proposed hypothesis is supported. Overall, it can be claimed that use of art activities (handcraft) increases the grade three female students' scores in fluency. Also the result reveals that both groups differ significantly in their performance of four different tasks/activities. (See table 4 below)

1.3. Hypothesis 3: Use of art activities (handcraft) increases the grade three female students' scores in originality

This proposed hypothesis is also stated in the form of null hypothesis in the following way:

Null Hypothesis 3: Use of art activities (handcraft) doesn't increase the grade three female students' scores in originality

In order to find of the difference between two groups in their score in originality and doing different activities, descriptive statistics was carried out. The result of descriptive statistics has been indicated in Table 5 .

The result of descriptive statistics reveals that the there is a difference between the mean score of the control and experimental groups. Students in the experimental group, $\mathrm{M}=6.23, \mathrm{SD}=5.32$ scored higher than the learners in the comparison group, $\mathrm{M}=4.53, \mathrm{SD}=3.63$.

To test the significance of the observed difference and test the proposed hypothesis another two-way ANOVA was carried out (see Table 6) The attained F-value for the between group difference was 9.63. The acquired significance for the difference between the scores of the groups was 0.002 which is less than the established 0.05 , therefore; the difference between groups is significant statistically, $\mathrm{F}(1,252)=9.63, \mathrm{P}<.005$. As a result, the third null hypothesis 
is rejected and accordingly the proposed hypothesis is supported safely. It is concluded that the use of art activities (handcraft) enhances the grade three female students' scores in originality.

\subsection{Hypothesis 4: Use of art activities (handcraft) increases the grade three female students' scores in flexibility}

The null hypothesis for this hypothesis is stated as the following.

Null Hypothesis 4: Use of art activities (handcraft) does not increase the grade three female students' scores in flexibility

Table 7 summarizes the descriptive statistics for this part. It indicates the number of the students, mean and standard deviation of scores in both experimental and control groups in performing different kinds of tasks. It is evident that the experimental group, $\mathrm{M}=7.07, \mathrm{SD}=2.77$ performed better in flexibility than the control group, $\mathrm{M}=6.34, \mathrm{SD}=$ 3.31 .

Like the previous hypotheses in order to find the significance of the difference between the mean score of the groups, an ANOVA analysis was carried out. The result of this analysis has been indicated in Table 8. As can be seen the F-value for the comparison between the mean of the groups is 4.017 and since its sig.(.047) is less than 0.05, it can be concluded that the difference between the groups is significant, $F(1,189)=4.017, p<0.05$. Hence, we can safely reject the null hypothesis and can claim that the use of art activities (handcraft) increases the grade three female students' scores in flexibility. Also, as indicated in the result of analysis, there is significant difference between the mean score of different activities done during the experiment, $F(2,189)=31.47$.

\subsection{Hypothesis 5: Use of art activities (handcraft) increases the grade three female students' scores in creativity}

Null Hypothesis 5: Use of art activities (handcraft) does not increase the grade three female students' scores in creativity

In order to compare the learners' creativity score in the experimental and control group, descriptive statistics were calculated by using SPSS package. The result of descriptive analysis has been shown in table 9.

From the result in this table it is evident that the creativity scores of the students in the experimental group is higher than those in the control group in performing all four tasks. Similarly, total mean score of the experimental group, $\mathrm{M}=7.21, \mathrm{SD}=6.41$ is higher than the mean score of the control group, $\mathrm{M}=4.70, \mathrm{SD}=3.51$.

Like earlier hypotheses, to test the significance of the acquired difference, another two-way ANOVA was carried out. The result of this analysis has been illustrated in table 10 below.

As it is evident from the above the ANOVA analysis, the difference between experimental group and control group is significant statistically, $\mathrm{F}(1,252)=16.15, \mathrm{P}<0.05$. Similarly, the difference between the scores of the groups in performing different activities is significant, $\mathrm{F}(3,252)=62.12, \mathrm{P}<0.05$. Consequently, the null hypothesis is rejected and the proposed hypothesis is supported strongly. It can be gathered that both groups differ significantly in their creativity score in performing four different tasks. It seems that those students who go through the handcraft making activities during the semester, have better enhancement in creativity than those students who don't do any handcraft making activities in the classroom.

\section{Conclusion and Discussion}

The result of data analysis demonstrates that using handcraft as an instrument has a significant influence on enhancing students' score in originality, flexibility and elaboration at the elementary grades, whereas; there is not any significant difference between their scores in fluency. It seems that using hand craft making activities in the classes at the elementary levels enhances the students' creativity skills but those students who don't go through handcraft making activities don't improve in their creativity.

It can be assumed that using handcraft making activities enhances their imagination which in own turn causes the growth of creativity and innovation among the learners. Using handcraft making activities causes learners to think analytically and make them study the natural events and things around deeply. Since using hand craft making activities leads to different mental experiences and can bring different flexibility opportunities for the learners, they can enrich their knowledge and self building abilities. Meanwhile, since handcraft making entails the learners' collaboration, it creates an opportunity for them to learn from their peers which may enhance their creativity. Therefore, it can be assumed that hand craft making activities unlike the other limiting and uncreative activities can help them promote their creativities in learning different things and enhance their abilities in creating new idea in tackling their learning issues.

Given the importance of creativity in learning, proposing a way to enhance it is of great significance to the educators and task designers in the field. The result may give some insights to the syllabus and task designers for elementary school students. In order to improve the creativity of the learners at lower levels, syllabus and task designers can include and use handcraft making activities in the materials or tasks they design. This would enhance students' 
creativity and at the same time would promote the quality of education and learners' achievement at higher levels. Similarly, based on the attained results in this study, the educators at the elementary levels are recommended to make use of activities that enhances their learners' creativity.

\section{References}

AbbasZadeh, M. (1994). Art in schools. Tehran: Maddrese Publications.

Amiri, S. (2007). The revolutionary trend of the creativity among children. The New Findings in Cognitive Science in the Ninth Year, 4, 27-35.

Amini, M. (2007). Art training within the scope of educational system. Tehran: Abijan Publication.

Callagher, J.J.(1985). Teaching the Gifted Child. New York: Allan and Bacon.

Catzeles, J.W. \& Jackson, P.W. (1962). Creativity and intelligence. New York: John \& willy

Croply A. J. (2001). Greativity in education and learning: A Guide for teachers and educators. Landon Keganpawl.

Delavar, A. (1999). Research Methodology in psychology and educational Science. Tehran: Virayesh Publication.

Getzels J.W. (1997). Creativity and Human Development: The Foundation of student's Learning. Pargamon Press.

Guillford, J. P. (1965). Implications of Research on Creativity. In: G. Banks and P.L. Broadhurst (Eds.). Studies in Psychology presented to Cyril Burt. London: University of London Press.

Guillford, J. P. (1965). Creativity, American Psychologist, 5, 444-454.

Hoseini A. (2007). The effect of teaching creativity on the learners'enhancement in creativity and pedagogical achievement. Educational Innovations, 23, 6-15.

Jahani J. (2006). A critical and Comparative Exploration of the Effect of Creativity Education on the Enhancement of Children' creativity. Social Science and Human Science Journal, 25, 4- 9.

Khosronejad, M. (1995). Creativity or Sociability? An Attempt to piece together a paradox. Esfahan: Public Education Publications, Educational Ministry of Esfahan

Lancaster, J. (1990). Art in primary school. London: Routledge

Mellow, M. (1992). Can Creativity by nurtured in young children. Early Child Development and Care, 13(2), 49-159.

Piaget, J. (1960). The Child's Conception of Physical Causality. New Jersey, NY: Littlefield, Adams.

Piaget, J. (1963). The Origins of Intelligence in Children. New York, NY: W.W. Norton.

Torrance, E.P. (1966). "Torrance Test of Creative thinking" direction manual and scoring guide. Personnel Press, Printed in USA.

Zakariayi, M. (2008). Studying the impact of Story telling and performing plays on the learners' creativity at the lower grades. Unpublished Ph.D Dissertation. Tehran: Azad University.

Table 1. Mean and standard deviation in three activities of fluency

\begin{tabular}{llll}
\hline Group & Activity & M & SD \\
\hline $\operatorname{Exp}(\mathrm{n}=32)$ & 2 & 10.75 & 4.33 \\
& 3 & 8.62 & 2.38 \\
& 4 & 6.44 & 2.21 \\
$\operatorname{Cont}(\mathrm{n}=31)$ & 2 & 11.77 & 3.58 \\
& 3 & 7.42 & 1.77 \\
& 4 & 5.39 & 1.56 \\
\hline
\end{tabular}

Table 2. Results of ANOVA: Comparison of group means in three activities for fluency

\begin{tabular}{lllll}
\hline Source & SS & df & M.S & F \\
\hline Intercept & 13328.85 & 1 & 13328.85 & 1671.02 \\
Group & 7.96 & 1 & 7.96 & .99 \\
Activity & 914.72 & 2 & 457.36 & $57.34^{* *}$ \\
G*Aa & 48.81 & 2 & 24.41 & $3.06^{*}$ \\
Error & 1459.70 & 183 & 7.98 & \\
\hline Total & 15768.000 & 189 & & \\
\hline
\end{tabular}


$* \mathrm{p}<0.05 * * \mathrm{p}<0.001$

a. interaction effect group and activity

Table 3. Mean and standard deviation in four activities of elaboration

\begin{tabular}{llll}
\hline Group & Activity & M & SD \\
\hline Exp $(\mathrm{n}=32)$ & 1 & 2.56 & .62 \\
& 2 & 3.91 & .30 \\
& 3 & 3.28 & .81 \\
& 4 & 4.13 & 1.01 \\
$\operatorname{Cont}(\mathrm{n}=31)$ & 1 & 1.97 & .55 \\
& 2 & 3.55 & .62 \\
& 3 & 3.39 & .95 \\
& 4 & 3.55 & .62 \\
\hline
\end{tabular}

Table 4. Results of ANOVA: Comparison of group means in four activities for elaboration

\begin{tabular}{lllll}
\hline Source & SS & df & M.S & F \\
\hline Intercept & 2728.36 & 1 & 2728.36 & 5273.44 \\
Group & 7.97 & 1 & 7.97 & $15.42^{* *}$ \\
Activity & 97.15 & 3 & 32.38 & $62.59^{* *}$ \\
G*Aa & 5.02 & 3 & 1.67 & $3.24^{*}$ \\
Error & 2970.00 & 244 & .52 & \\
\hline Total & 2970.00 & 252 & & \\
\hline
\end{tabular}

${ }^{*} \mathrm{p}<0.05 * * \mathrm{p}<0.001$

a. interaction effect group and activity

Table 5. Mean and standard deviation in four activities of originality

\begin{tabular}{llll}
\hline Group & Activity & M & SD \\
\hline Exp $(\mathrm{n}=32)$ & 1 & 4.97 & 1.96 \\
& 2 & 4.91 & 3.37 \\
& 3 & 8.31 & 7.55 \\
& 4 & 6.72 & 5.96 \\
$\operatorname{Cont}(\mathrm{n}=31)$ & 1 & 3.13 & 1.82 \\
& 2 & 4.19 & 2.95 \\
& 3 & 7.48 & 4.57 \\
& 4 & 3.32 & 2.90 \\
\hline
\end{tabular}

Table 6. Results of ANOVA: Comparison of means groups in four activities for originality

\begin{tabular}{lllll}
\hline Source & SS & df & M.S & F \\
\hline Intercept & 7290.55 & 1 & 7290.55 & 388.59 \\
Group & 180.81 & 1 & 180.81 & $9.64^{*}$ \\
Activity & 562.53 & 3 & 187.51 & $9.99^{* *}$ \\
G*Aa & 72.91 & 3 & 24.30 & 1.29 \\
Error & 4577.87 & 244 & 18.76 & \\
\hline Total & 12721.00 & 252 & & \\
\hline
\end{tabular}

$* \mathrm{p}<0.01 \quad * * \mathrm{p}<0.001$

a. interaction effect group and activity 
Table 7. Mean and standard deviation in three activities of flexibility

\begin{tabular}{llll}
\hline Group & Activity & M & SD \\
\hline Exp $(\mathrm{n}=32)$ & 2 & 7.69 & 3.14 \\
& 3 & 6.16 & 1.53 \\
& 4 & 7.38 & 3.15 \\
$\operatorname{Cont}(\mathrm{n}=31)$ & 2 & 9.77 & 3.11 \\
& 3 & 4.77 & 1.45 \\
& 4 & 4.48 & 1.88 \\
\hline
\end{tabular}

Table 8. Results of ANOVA: Comparison of means groups in three activities for flexibility

\begin{tabular}{llllll}
\hline Source & SS & df & M.S & F \\
\cline { 2 - 6 } Intercept & 8503.61 & 1 & 8503.61 & 1361.26 \\
Group & 25.09 & 1 & 25.09 & $4.02^{*}$ \\
Activity & 393.18 & 2 & 196.59 & $31.47^{* *}$ \\
G*Aa & 205.16 & 2 & 102.58 & $16.42^{* *}$ \\
Error & 1143.17 & 183 & 6.25 & \\
\hline Total & 10279.00 & 189 & & \\
\hline
\end{tabular}

$* \mathrm{p}<0.05 \quad * * \mathrm{p}<0.001$

a. interaction effect group and activity

Table 9. Mean and standard deviation in four activities of creativity

\begin{tabular}{llll}
\hline Group & Activity & M & SD \\
\hline $\operatorname{Exp}(\mathrm{n}=32)$ & 1 & 3.69 & 1.45 \\
& 2 & 5.91 & 4.37 \\
& 3 & 9.33 & 8.52 \\
& 4 & 7.63 & 6.85 \\
$\operatorname{Cont}(\mathrm{n}=31)$ & 1 & 2.89 & 1.30 \\
& 2 & 4.92 & 3.98 \\
& 3 & 7.56 & 5.61 \\
& 4 & 6.25 & 5.88 \\
\hline
\end{tabular}

Table 10. Results of ANOVA: Comparison of means groups in four activities for creativity

\begin{tabular}{lllll}
\hline Source & SS & df & M.S & F \\
\hline Intercept & 2831.28 & 1 & 2831.28 & 5321.37 \\
Group & 7.70 & 1 & 7.70 & $16.16^{* *}$ \\
Activity & 98.13 & 3 & 31.52 & $62.12^{* *}$ \\
G*Aa & 6.33 & 3 & 1.92 & $3.34^{*}$ \\
Error & 131.11 & 244 & .62 & \\
\hline Total & 2971.00 & 252 & & \\
\hline
\end{tabular}

$* \mathrm{p}<0.05^{* *} \mathrm{p} \leq 0.001$

a. interaction effect group and activity 